\title{
Cefepime, a fourth-generation cephalosporin, in complex with manganese, inhibits proteasome activity and induces the apoptosis of human breast cancer cells
}

\author{
ZHEN ZHANG $^{1}$, CAIFENG BI ${ }^{2}$, YUHUA FAN ${ }^{2}$, HUANNAN WANG ${ }^{3}$ and YAN BAO ${ }^{2}$ \\ ${ }^{1}$ School of Pharmacy, Jining Medical University, Rizhao, Shandong 276826; ${ }^{2}$ Key Laboratory of Marine Chemistry Theory \\ and Technology, Ministry of Education, College of Chemistry and Chemical Engineering, Ocean University of China, \\ Qingdao, Shandong 266100; ${ }^{3}$ Neurobiology Institute, Jining Medical University, Jining, Shandong 272100, P.R. China
}

Received January 17, 2015; Accepted July 20, 2015

DOI: $10.3892 / \mathrm{ijmm} .2015 .2297$

\begin{abstract}
Cefepime (FEP), which is a member of the fourthgeneration cephalosporin class, has been extensively studied as a biochemical and antimicrobial reagent in recent years. Manganese (Mn) is important in the biochemical and physiological processes of many living organisms, and it is also high expressed in some tumor tissues. In the present study, we aimed to investigate the proteasome-inhibitory and anti-proliferative properties of 8 metal complexes (FEP-Cu, FEP-Zn, FEP-Co, FEP-Ni, FEP-Cd, FEP-Cr, FEP-Fe, FEP-Mn) in MDA-MB-231 human breast cancer cells. The FEP-Mn complex was found to be more potent in its ability to inhibit cell proliferation and proteasome activity than the other compounds tested. Moreover, the FEP-Mn complex inhibited proteasomal chymotrypsin-like (CT-like) activity and induced the apoptosis of breast cancer cells in a dose-and time-dependent manner. Furthermore, the MCF-10A cells were much less sensitive to the FEP complexes compared with the MDA-MB-231 breast cancer cells. These results demonstrated that the FEP-Mn(II) complex has the potential to act as a proteasome inhibitor and apoptosis inducer and therefore has possible future applications in cancer chemotherapy.
\end{abstract}

Correspondence to: Dr Zhen Zhang, School of Pharmacy, Jining Medical University, 669 Xueyuan Road, Rizhao, Shandong 276826, P.R. China

E-mail: zhangzhen_1029@126.com

Dr Caifeng Bi, Key Laboratory of Marine Chemistry Theory and Technology, Ministry of Education, College of Chemistry and Chemical Engineering, Ocean University of China, 238 Songling Road, Qingdao, Shandong 266100, P.R. China

E-mail: bcfeng@ouc.edu.cn

Key words: cefepime, manganese, proteasome inhibitor, apoptosis, antitumor activity

\section{Introduction}

Cefepime (FEP) is a member of the fourth-generation cephalosporin class with broad-spectrum activity against both Gram-positive and Gram-negative bacteria (1) that has been widely used for approved indications, such as febrile neutropenia, which is a major adverse effect in patients receiving cancer chemotherapy with or without radiotherapy (2-5). It is known that several drugs have better pharmacological properties when in the form of metal complexes (6). Thus, a number of cephalosporin metal complexes have been extensively studied as biochemical and antimicrobial reagents over the past decade (7-12). However, to date, only a few studies have investigated the antitumor activity of these metal complexes.

Manganese (Mn), an essential trace element required by the human body, has come to be recognized as being significant in many biological systems (13-15). A few papers have demonstrated that some Mn-based compounds possess superoxide dismutase (SOD)-like activity $(16,17)$ and may be considered as potential anti-Mycobacterium tuberculosis agents (18). In addition, some Mn complexes have also exhibited antitumor activity against a variety of cancer cells. For example, $\mathrm{Mn}$ (II) complexes of 6,7-dicycanodipyridoquinoxaline and 2H-5-hydroxy-1,2,5oxadiazo[3,4-f]1,10-phenanthroline have been found to exhibit antitumor activity due to DNA binding $(19,20)$. The $M n(I I)$ compound [(Adpa) $\left.\mathrm{Mn}(\mathrm{Cl})\left(\mathrm{H}_{2} \mathrm{O}\right)\right]$ (Adpa = bis(2-pyridylmethyl) amino-2-propionic acid) was reported to target the mitochondria and to inhibit the proliferation of U251 human glioma cells (21). Moreover, Mn(II) complexes of quinoline derivatives have potential as attenuators of $\mathrm{Ca}^{2+}$ absorption in the mitochondria and can interfere with the metabolism of $\mathrm{O}_{2}$ for cancer chemotherapy (22). The novel Mn(II) complexes of indolecarboxylic acids have been reported to display cytotoxicity and their antiproliferative activity against some cell lines (e.g., Jurkat derived from an acute $\mathrm{T}$ cell leukemia), is similar to that of cisplatin (23). However, although many studies have demonstrated that such $\mathrm{Mn}$ (II) complexes have potential for use as antitumor drugs, their mechanisms of action are not yet fully understood.

It is known that the ubiquitin-proteasome system (UPS) maintains protein homestasis in human cells, and it is involved 
in highly regulated cellular processes, including cell cycle progression, proliferation, apoptosis and differentiation $(24,25)$. It has been proven that the UPS is an important target in cancer treatment. The $20 \mathrm{~S}$ proteasome, the main component of the UPS, possesses multiple peptidase activities, such as caspaselike or peptidyl-glutamyl peptide-hydrolyzing-like (PGPH-like) activity ( $\beta 1$ subunit), trypsin like activity ( $\beta 2$ subunit) and chymotrypsin-like (CT-like) activity ( $\beta 5$ subunit) (26-28). However, only the inhibition of proteasomal CT-like activity has been shown to be closely associated with the induction of cancer cell death (29-31). In 2004, Daniel et al (32) found that mixtures of copper salts with the ligands (clioquinol, hydroxyquinoline and dithiocarbamate) inhibited the effect of the $20 \mathrm{~S}$ proteasome in vitro and in vivo. Therefore, the inhibition of proteasomal CT-like activity is associated with the induction of cancer cell apoptosis $(33,34)$ and is unquestionably linked to the presence of metal ions (35).

Previously, we found that certain types of copper(II) complexes, $\left[\mathrm{Cu}\left(\mathrm{C}_{10} \mathrm{H}_{8} \mathrm{O}_{2} \mathrm{~N}\right)_{2}\left(\mathrm{C}_{12} \mathrm{H}_{8} \mathrm{~N}_{2}\right)\right]$ and $\left[\mathrm{Cu}\left(\mathrm{C}_{11} \mathrm{H}_{10} \mathrm{O}_{2} \mathrm{~N}\right)_{2}\right.$ $\left.\left(\mathrm{C}_{12} \mathrm{H}_{8} \mathrm{~N}_{2}\right)\right]$, cadmium(II) complexes, $\left[\mathrm{Cd}_{2}\left(\mathrm{C}_{12} \mathrm{H}_{12} \mathrm{O}_{2} \mathrm{~N}\right)_{4}\right.$ $\left.\left(\mathrm{H}_{2} \mathrm{O}\right)_{2}\right] \cdot 2 \mathrm{H}_{2} \mathrm{O}, \quad\left[\mathrm{Cd}_{2}\left(\mathrm{C}_{11} \mathrm{H}_{10} \mathrm{O}_{2} \mathrm{~N}\right)_{4}\left(\mathrm{H}_{2} \mathrm{O}\right)_{2}\right] \cdot 2 \mathrm{H}_{2} \mathrm{O}$ and $\left[\mathrm{Cd}\left(\mathrm{C}_{7} \mathrm{H}_{4} \mathrm{~N}_{2} \mathrm{O}_{2}\right)\left(\mathrm{C}_{8} \mathrm{H}_{6} \mathrm{O}_{2}\right)_{2}\right] \cdot 2 \mathrm{H}_{2} \mathrm{O}$, may serve as potent, selective proteasome inhibitors and apoptosis inducers in cultured human cancer cells $(36,37)$. In this study, we investigated the effects of FEP-metal complexes on breast cancer cells. We found that only the FEP-Mn complex inhibited the CT-like activity of the proteasome in human breast cancer cell cultures and induced cancer cell death. Furthermore, the MDA-MB-231 breast cancer cells were more sensitive to the novel candidate FEP-Mn complex than normal cells. This suggests that the FEP-Mn complex has potential for use as a novel class of antitumor agents.

\section{Materials and methods}

Chemicals and reagents. FEP was purchased from Sinopharm Chemical Reagent Co., Ltd. (Shanghai, China). The chemical structure of FEP is illustrated in Fig. 1. Dimethylsulfoxide (DMSO) and the acetate $\left[\mathrm{Cu}\left(\mathrm{CH}_{3} \mathrm{COO}\right)_{2} \cdot \mathrm{H}_{2} \mathrm{O}\right.$, $\mathrm{Zn}\left(\mathrm{CH}_{3} \mathrm{COO}\right)_{2} \cdot 2 \mathrm{H}_{2} \mathrm{O}, \mathrm{Co}\left(\mathrm{CH}_{3} \mathrm{COO}\right)_{2} \cdot 4 \mathrm{H}_{2} \mathrm{O}, \mathrm{Ni}\left(\mathrm{CH}_{3} \mathrm{COO}\right)_{2} \cdot$ $4 \mathrm{H}_{2} \mathrm{O}, \mathrm{Mn}\left(\mathrm{CH}_{3} \mathrm{COO}\right)_{2} \cdot 4 \mathrm{H}_{2} \mathrm{O}, \mathrm{Cd}\left(\mathrm{CH}_{3} \mathrm{COO}\right)_{2} \cdot 2 \mathrm{H}_{2} \mathrm{O}, \mathrm{Cr}\left(\mathrm{NO}_{3}\right)_{3} \cdot$ $9 \mathrm{H}_{2} \mathrm{O}$ and $\mathrm{Fe}\left(\mathrm{NO}_{3}\right)_{3} \cdot 9 \mathrm{H}_{2} \mathrm{O}$ ] were all purchased from Aladdin Reagents Co. Ltd., (Shanghai, China). FEP and various metal salts were dissolved and formed new complexes [FEP-Cu (FEP1), FEP-Zn (FEP2), FEP-Co (FEP3), FEP-Ni (FEP4), FEP-Cr (FEP5), FEP-Cd (FEP6), FEP-Fe (FEP7), FEP-Mn (FEP8)] in DMSO to a final concentration of $50 \mathrm{mM}$ and stored at $4^{\circ} \mathrm{C}$. 3-(4,5-Dimethylthiazol-2-yl)-2,5-diphenyl-tetrazolium bromide (MTT) was purchased from Sigma-Aldrich (St. Louis, MO, USA). Dulbecco's modified Eagle's medium (DMEM)/ F-12 (1:1) and penicillin/streptomycin were purchased from Invitrogen Life Technologies (Carlsbad, CA, USA). Fetal bovine serum (FBS) was purchased from Aleken Biologicals (Nash, TX, USA). The fluorogenic peptide substrate SucLLVY-AMC (for the proteasomal CT-like activity) was obtained from Calbiochem (San Diego, CA, USA). Mouse monoclonal antibody against human poly(ADP-ribose) polymerase (PARP), mouse monoclonal antibodies against ubiquitin (P4D1) and IкB- $\alpha(\mathrm{H}-4)$, goat polyclonal antibody against $\beta$-actin $(\mathrm{C}-11)$ and all secondary antibodies were

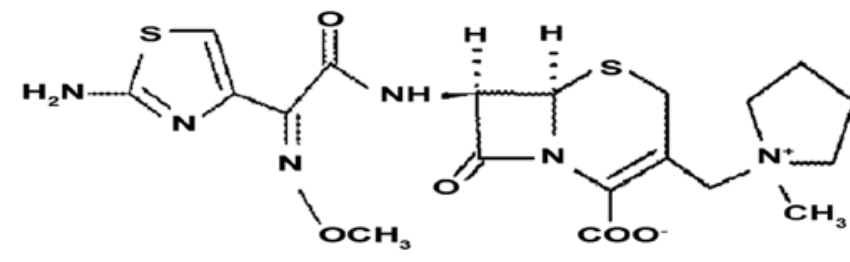

Figure 1. Chemical structure of cefepime (FEP).

purchased from Santa Cruz Biotechnology, Inc. (Santa Cruz, CA, USA).

Cell culture and whole cell extract preparation. MDA-MB-231 human breast cancer cells were grown in DMEM/F-12 (1:1) supplemented with $10 \%$ FBS, $100 \mathrm{U} / \mathrm{ml}$ of penicillin and $100 \mu \mathrm{g} / \mathrm{ml}$ of streptomycin. MCF-10A cells (immortalized, but non-tumorigenic) were cultured in 1:1 DMEM/F-12 supplemented with 5\% (v/v) horse serum, $0.029 \mathrm{~mol} / \mathrm{l}$ sodium bicarbonate, $10 \mathrm{mM}$ HEPES buffer solution, $100 \mathrm{U} / \mathrm{ml}$ of penicillin, $5 \mathrm{mg}$ insulin, $10 \mu \mathrm{g}$ of epidermal growth factor and $250 \mu \mathrm{g}$ hydrocortisone. The cell lines were maintained at $37^{\circ} \mathrm{C}$ in an atmosphere containing $5 \% \mathrm{CO}_{2}$. The whole cell extracts were prepared as previously described (38). Briefly, the cells were harvested, lysed and the supernatants were collected as whole-cell extracts which were used for western blot analysis.

Cell proliferation assays. The effect of each FEP-metal complex on cell proliferation was determined by MTT assay. MDA-MB-231 and MCF-10A cells were seeded in triplicate in a 96-well plate, grown to 70-80\% confluence, and then treated with the indicated concentration of each FEP-metal complex. After $48 \mathrm{~h}$ of incubation at $37^{\circ} \mathrm{C}$, the inhibition of cell proliferation was measured as previously described (38).

Inhibition of purified $20 \mathrm{~S}$ proteasome activity by the FEP-Mn complex. The CT-like activity of the purified human $20 \mathrm{~S}$ proteasome was measured as previously described (32). Briefly, $35 \mathrm{ng}$ of purified $20 \mathrm{~S}$ proteasome were incubated in $100 \mu \mathrm{l}$ of assay buffer ( $20 \mathrm{mM}$ Tris-HCl, $\mathrm{pH}$ 7.5) with or without various concentrations of the FEP-Mn complex and $20 \mu \mathrm{M}$ of CT-like substrate Suc-LLVY-AMC (for the proteasomal CT-like activity) for $2 \mathrm{~h}$ at $37^{\circ} \mathrm{C}$. Following incubation, proteasome CT-like activity was measured using the Wallac Victor 3 multilabel counter with an excitation filter of $365 \mathrm{~nm}$ and emission filter of $460 \mathrm{~nm}$.

Analysis of proteasomal CT-like activity in whole-cell extracts. Whole-cell extracts (10 $\mu \mathrm{g})$ of MDA-MB-231 breast cancer cells were incubated for $2 \mathrm{~h}$ at $37^{\circ} \mathrm{C}$ in $100 \mu \mathrm{l}$ of assay buffer $(20 \mathrm{mmol} / 1$ Tris-HCl, pH 7.5) with $20 \mu \mathrm{mol} / 1$ fluorogenic peptide substrate Suc-LLVY-AMC (for the proteasomal CT-like activity), followed by measurement of AMC group release, as described above.

Western blot analysis. Breast cancer cells were treated with the different complexes as indicated in the figure legends. Cells treated with DMSO served as the controls. After $24 \mathrm{~h}$ of treatment, the cells were harvested and lysed. Protein $(40 \mu \mathrm{g})$ from whole-cell extracts was separated by sodium dodecyl sulfate 


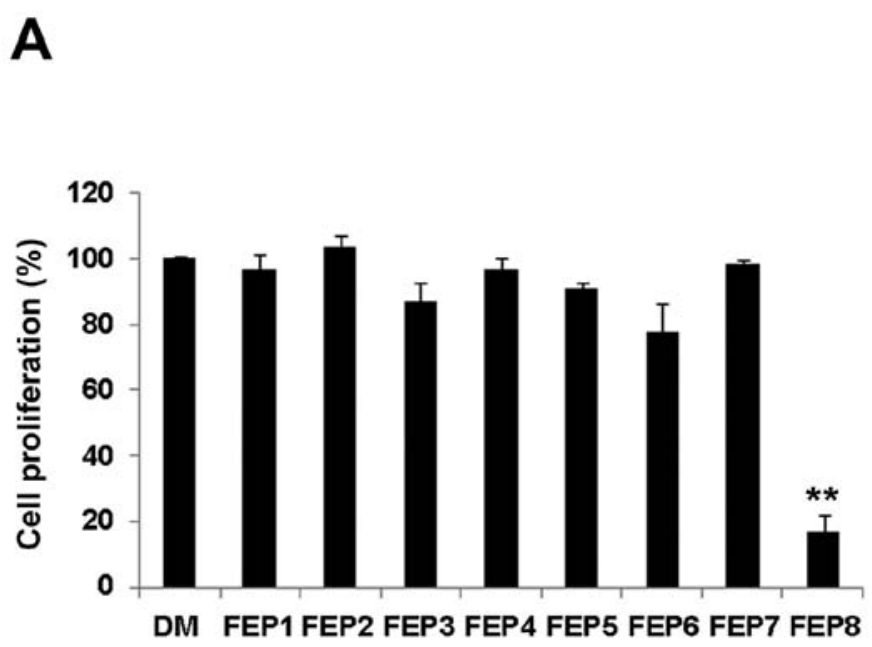

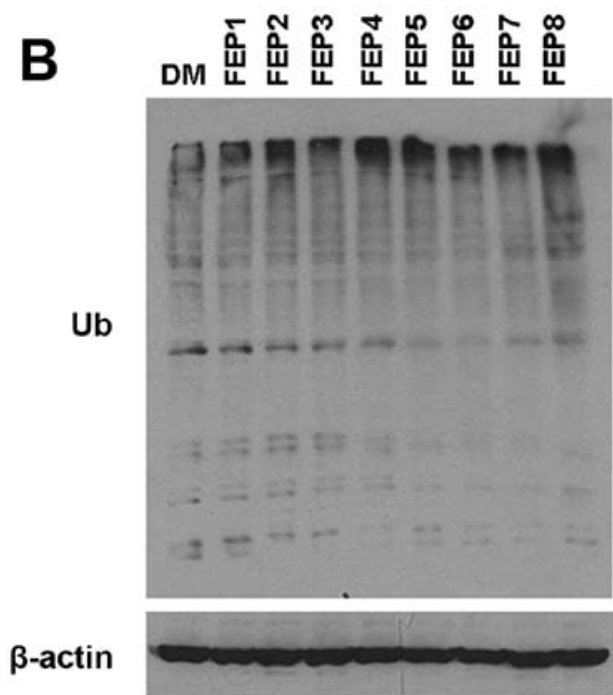

Figure 2. Comparison of cell proliferation and proteasome inhibition in MDA-MB-231 cells treated with the cefepime and metal complexes (FEP1-FEP8). MDA-MB-231 cells were treated with $40 \mu \mathrm{M}$ of each indicated compound for $24 \mathrm{~h}$. (A) MTT assay was performed to assess cell proliferation. ${ }^{* *} \mathrm{P}<0.01$, compared to other treatments. Bars indicate the means \pm SD of 3 independent experiments. (B) Western blot analysis of polyubiquitinated proteins was performed $\beta$-actin was used as a loading control.

polyacrylamide gel electrophoresis (SDS-PAGE) and transferred onto a nitrocellulose membrane. Western blot analysis was performed using specific antibodies to ubiquitin, IкB- $\alpha$, PARP, and $\beta$-actin, followed by visualization with an enhanced chemiluminescence reagent, as previously described (39).

Analysis of cell morphology. Changes in cell morphology were observed using a Zeiss Axiovert 25 phase contrast microscope (Zeiss, Oberkochen, Germany). Rounded and detached cells were considered apoptotic.

Statistical analysis. Statistical analysis was performed using Microsoft Excel software. Differences between groups were analyzed using the Student's t-test. All data are presented as the means \pm SD.

\section{Results}

FEP forms new complexes with different metal salts in solution. Several previous studies have reported that many complexes, such as clioquinol-copper (40), the ternary complexes, indole-3-acetic acid-copper-phenanthroline (phen) and indole-3-propionic-copper-phen (36), taurine and L-glutamine Schiff base copper complexes $(41,42)$, zinc, nickel, cadmium complexes and so on, are capable of inhibiting cell proliferation and proteasome activity, and inducing the apoptosis of human cancer cells $(37,43,44)$. However, to the best of our knowledge, the effects of Mn(II) complexes on cancer cells have not been reported to date. In the current study, FEP was mixed with various metal salts, dissolved in DMSO at a concentration of $50 \mathrm{mM}$, in a 1:1 molar ratio. The reaction of FEP with the different metal salts resulted in a marked change in color, which indicated that a chemical reaction had occurred and the complexes had formed (data not shown). In this study, we focused on the FEP-metal complex solution and investigated the effects of this complex on human breast cancer cells.
Antiproliferative and proteasome-inhibitory effects of FEP1-FEP8 in MDA-MB-231 breast cancer cells. For this portion of the study, the FEP1-FEP8 complexes were investigated for their growth inhibitory effects on MDA-MB-231 breast cancer cells at the concentration of at $40 \mu \mathrm{M}$ of each compound for $24 \mathrm{~h}$. Cells treated with DMSO were used as a control. Of note, the most effective compound was found to be FEP8, the FEP-Mn complex, which induced the greatest decrease in the proliferation of MDA-MB-231 cells, causing a $>83 \%$ growth inhibition after $24 \mathrm{~h}$ of treatment (Fig. 2A). However, all the other FEP-metal complexes caused little or no growth inhibition of MDA-MB-231 breast cancer cells (Fig. 2A).

We then measured the ability of complexes FEP1-FEP8 to inhibit proteasome activity. The MDA-MB-231 cells were treated with $40 \mu \mathrm{M}$ of each compound for $24 \mathrm{~h}$ and the effect on accumulated ubiquitinated proteins was assessed. The results of western blot analysis confirmed that the FEP-Mn complex was a potent proteasome inhibitor. The accumulation of ubiquitinated proteins was observed in the cells treated with FEP8, but not in the cells treated with the other complexes (Fig. 2B). Thus, our results suggest that FEP8 is more potent in its ability to inhibit cell proliferation and proteasome activity than the other compounds tested (FEP1-FEP7).

In our previous studies, we demonstrated that a number of organic copper- and cadmium-based complexes were capable of inhibiting the tumor cell proteasome and thus, cell proliferation, thereby inhibiting cancer cell growth $(36,37)$. It was of interest to determine whether this was also an effect of the Mn complex.

Inhibition of purified 20 S proteasome activity by FEP8. To investigate the effects of the Mn complex, we also carried out in vitro assays using the purified $20 \mathrm{~S}$ proteasome, which was treated with various concentrations of FEP8 and with DMSO as a control. The results revealed that this Mn complex is capable of inhibiting the CT-like activity of the purified 


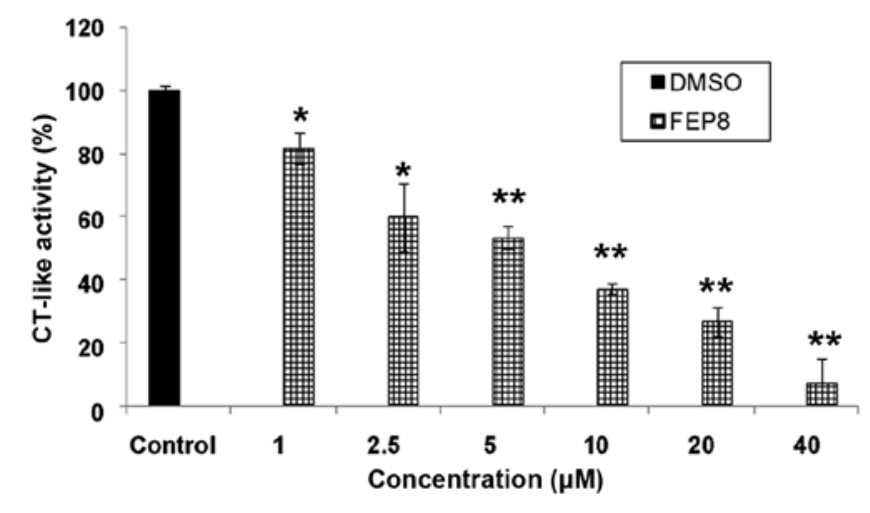

Figure 3. Purified 20S proteasome inhibition by the cefepime and manganese complex (FEP8). Purified human 20S proteasome (35 ng) was incubated with dimethylsulfoxide (DMSO) or various concentrations of FEP8 for $2 \mathrm{~h}$, and a proteasomal chymotrypsin (CT)-like activity assay was performed. ${ }^{*} \mathrm{P}<0.05$ and ${ }^{* *} \mathrm{P}<0.01$, compared to control. Bars indicate the means \pm SD of 3 independent experiments.

20S proteasome (Fig. 3). This indicated that the FEP-Mn complex targeted the $20 \mathrm{~S}$ proteasomal catalytic $\beta 5$ subunit. This is consistent with the results of our previous studies $(36,37)$, which demonstrated that copper and cadmium complexes have the potential to serve as potent, selective proteasome inhibitors.

Inhibition of CT-like activity and induction of apoptosis by FEP8 in MDA-MB-231 breast cancer cells. In the previous section, we have discussed the inhibition of proteasomal CT-like activity under cell-free conditions. We then sought to determine whether this effect is dose dependent in cancer cells. The MDA-MB-231 cells were treated with FEP8 at concentrations of 20,30, 40 and $50 \mu \mathrm{M}$. Cells treated with DMSO were used as a vehicle control. After $24 \mathrm{~h}$ of treatment, the cells were collected and cell extracts were prepared for the determination of the extent of proteasome inhibition. The inhibition of cellular proteasome activity was measured as the decreased levels of CT-like activity and the accumulation of ubiquitinated proteins, as previously described (45).

The results revealed that FEP8 inhibited the proteasomal CT-like activity in a dose-dependent manner by approximately $40 \%$ at $20 \mu \mathrm{M}, 70 \%$ at $30 \mu \mathrm{M}, 82 \%$ at $40 \mu \mathrm{M}$ and $92 \%$ at $50 \mu \mathrm{M}$ (Fig. 4A). Consistently, the dose-dependent accumulation of ubiquitinated proteins was also observed in the MDA-MB-231 breast cancer cells treated with FEP8 (Fig. 4B). It has been reported that the inhibition of the proteasomal CT-like activity is associated with the apoptosis of cancer cells (34).

In the same experiment, we then evaluated the apoptosisinducing effect of FEP8 in breast cancer cells. The cleaved p85 fragment of PARP was observed at an FEP8 concentration of $50 \mu \mathrm{M}$ (Fig. 4B), indicating the induction of cell apoptosis. To further investigate the apoptosis-inducing effect of FEP8, we examined changes in cell morphology. Treatment with FEP8 induced the rounding and shrinkage of the MDA-MB-231 cells (Fig. 4C) in a concentration-dependent manner. These results demonstrated that FEP8 possesses the ability to inhibit proteasome activity and is able of inducing the apoptosis of MDA-MB-231 human breast cancer cells in a dose-dependent manner.

Time-dependet effect of FEP8 on proteasome inhibition and induction of apoptosis in MDA-MB-231 breast cancer cells. In order to examine the time-dependent effect of FEP8-induced proteasome inhibition, the MDA-MB-231 cells were treated with $20 \mu \mathrm{M}$ of FEP8 for 3, 9, 24 or $48 \mathrm{~h}$ (DMSO-treated cells were used as a vehicle control), followed by the measurement of proteasome activity (Fig. 5). Proteasomal CT-like activity
A

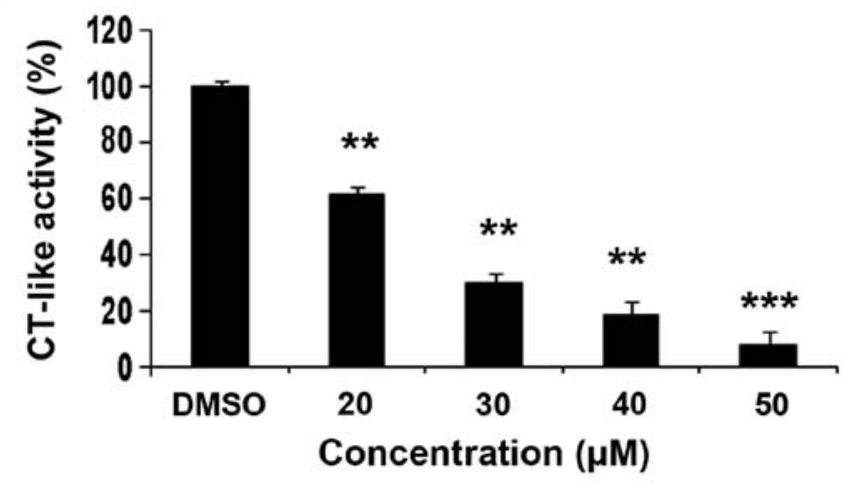

C

DM

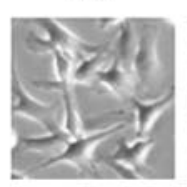

20

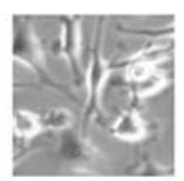

30

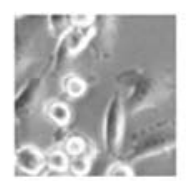

40

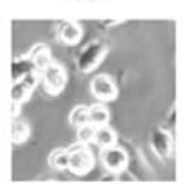

$50 \quad(\mu \mathrm{M})$

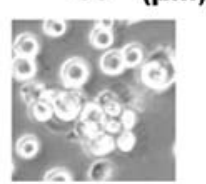

B

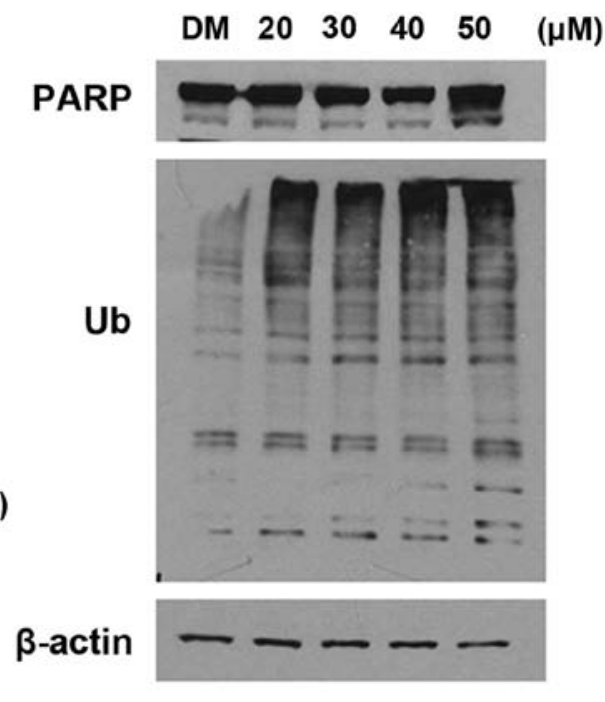

Figure 4. Effect of various concentrations of the cefepime plus manganese complex (FEP8) on MDA-MB-231 breast cancer cells. MDA-MB-231 cells were treated with dimethylsulfoxide (DMSO) (as a control) or various concentrations of FEP8 for 24 h. (A) Chymotrypsin $(\mathrm{CT})$-like activity assay. ${ }^{* *} \mathrm{P}<0.01$ and ${ }^{* * *} \mathrm{P}<0.001$, compared to control. Bars indicate the means \pm SD of 3 independent experiments. (B) Western blot analysis of polyubiquitinated proteins and poly(ADP-ribose) polymerase (PARP), and (C) analysis of changes in cell morphology was performed. 
A

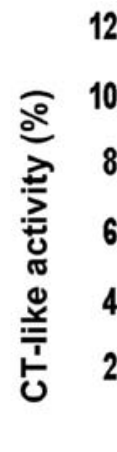

20
C

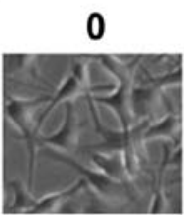

3

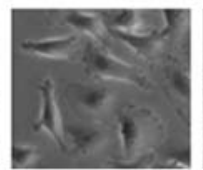

3

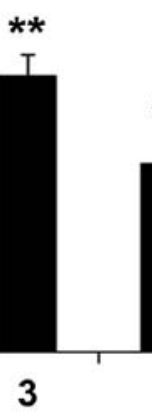

9

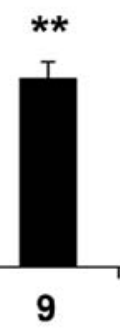

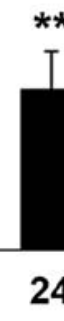

\section{$* *$}
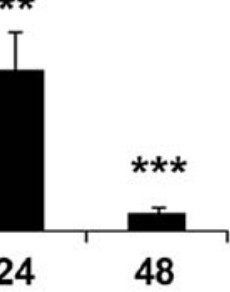

(h)

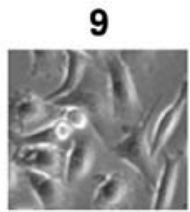
24
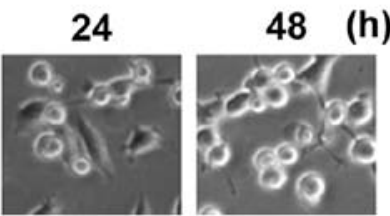

B

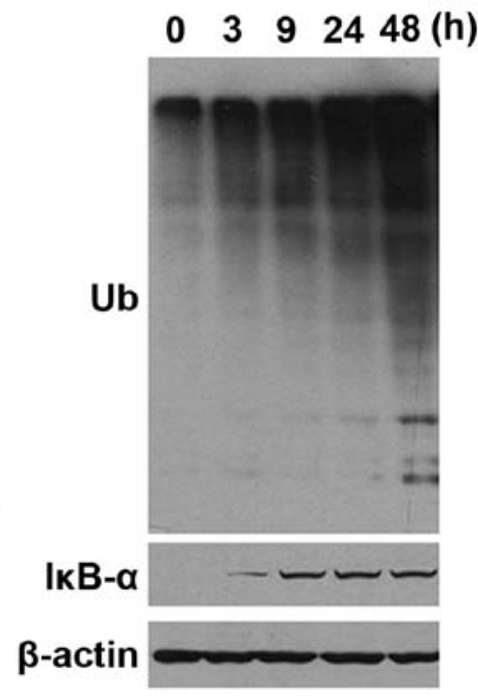

Figure 5. Time-dependent effect of proteasome inhibition and the induction of apoptosis by the cefepime plus manganese complex (FEP8) in MDA-MB-231 cells. MDA-MB-231 cells were exposed to $20 \mu \mathrm{M}$ of FEP8 for the indicated periods of time. (A) Proteasomal chymotrypsin (CT)-like activity assay. ${ }^{* *} \mathrm{P}<0.01$ and ${ }^{* * * *} \mathrm{P}<0.001$, compared to control. Bars indicate the means \pm SD of 3 independent experiments. (B) Western blot assay (ubiquitin, IкB- $\alpha$ and $\beta$-actin), and (C) analysis of morphological changes associated with apoptotic cells were performed. The appearance of rounded and detached cells, indicative of apoptosis, gradually increased as time progressed.

was inhibited by FEP8 in a time-dependent manner, as early as $3 \mathrm{~h}$, with $\sim 20 \%$ inhibition (Fig. 5A). The CT-like activity was further decreased at subsequent time-points, with 45,55 or $95 \%$ inhibition observed after 9, 24 and 48 h, respectively (Fig. 5A). Furthermore, the inhibition of proteasomal CT-like activity was associated with the gradual accumulation of ubiquitinated proteins, starting at $3 \mathrm{~h}$ and peaking at $48 \mathrm{~h}$ (Fig. 5B). Additionally, higher levels of the proteasomal target protein, I $\mathrm{B}-\alpha$, were also observed at $3 \mathrm{~h}$ post-treatment and later time-points (Fig. 5B). In the same time-dependent experiment, abnormal morphological changes were not detected until $9 \mathrm{~h}$ post-treatment with FEP8. Moreover, the appearance of rounded and detached cells, indicative of apoptosis, gradually increased as time progressed (Fig. 5C). These results clearly indicte that FEP8 induces proteasome inhibition, followed by the induction of apoptosis in breast cancer cells. Therefore, the apoptosis induced by FEP8 is a consequence of proteasome inhibition.

Less toxic effect of FEP8 on immortalized, non-tumorigenic MCF-10A breast cells compared with MDA-MB-231 breast cancer cells. It is imperative for effective anticancer drugs to have the ability to distinguish between normal and cancer cells (46-48). Thus, to investigate whether FEP8 exhibited selectivity toward cancer cells, but not normal cells, we used the MDA-MB-231 breast cancer cells and normal immortalized MCF-10A human breast cells. The two cell lines were treated with various concentrations of FEP8 for $24 \mathrm{~h}$, and with DMSO as a control, followed by the measurement of cell proliferation and the observation of changes in cell morphology. When FEP8 was used at a concentration of $10 \mu \mathrm{M}$, no inhibition of cell proliferation was observed in the MCF-10A cells, whereas $\sim 20 \%$ inhibition of proliferation was observed in the MDA-MB-231 cells (Fig. 6A). FEP8 exhibited markedly different effects on cell proliferation when the two cell lines were treated with FEP8 at concentrations ranging from 20 to $50 \mu \mathrm{M}$, causing $56,76,87$ and $95 \%$ growth inhibition of MDA-MB-231 breast cancer cells and 5, 14, 25 and 30\% inhibition of non-tumorigenic MCF-10A cells, respectively (Fig. 6A). In this regard, it may be concluded that FEP8 is a potent inhibitor of MDA-MB-231 cell proliferation, but that it is less toxic to non-tumorigenic MCF-10A breast cells, thus rendering our novel $\mathrm{Mn}$ complexes more favorable for further preclinical studies.

Additionally, under the same conditions, morphological changes were meaningful in determining whether FEP8 induces less apoptosis in normal MCF-10A cells compared with MDA-MB-231 breast cancer cells (Fig. 6B). Shrunken and rounded MDA-MB-231 cells were observed following treatment with various concentrations of FEP8, whereas little or nearly no morphological changes were observed in the MCF-10A cells (Fig. 6B), which was consistent with the results of MTT assay. Taken together, our results suggest that FEP8 inhibits cell proliferation and induces apoptosis selectively in human cancer cells and exerts less toxic effects on normal immortalized breast cells.

\section{Discussion}

Since the discovery of the antitumor activity of cisplatin and its analogs, novel metal complexes have been studied extensively in chemotherapy (49). Mn is important in the biochemical and physiological processes of many living organisms (50). Mn is also highly expressed in some tumor tissues (51). Based on the biological function of Mn, many Mn complexes have been reported to exert anticancer activity in some cancer cell 


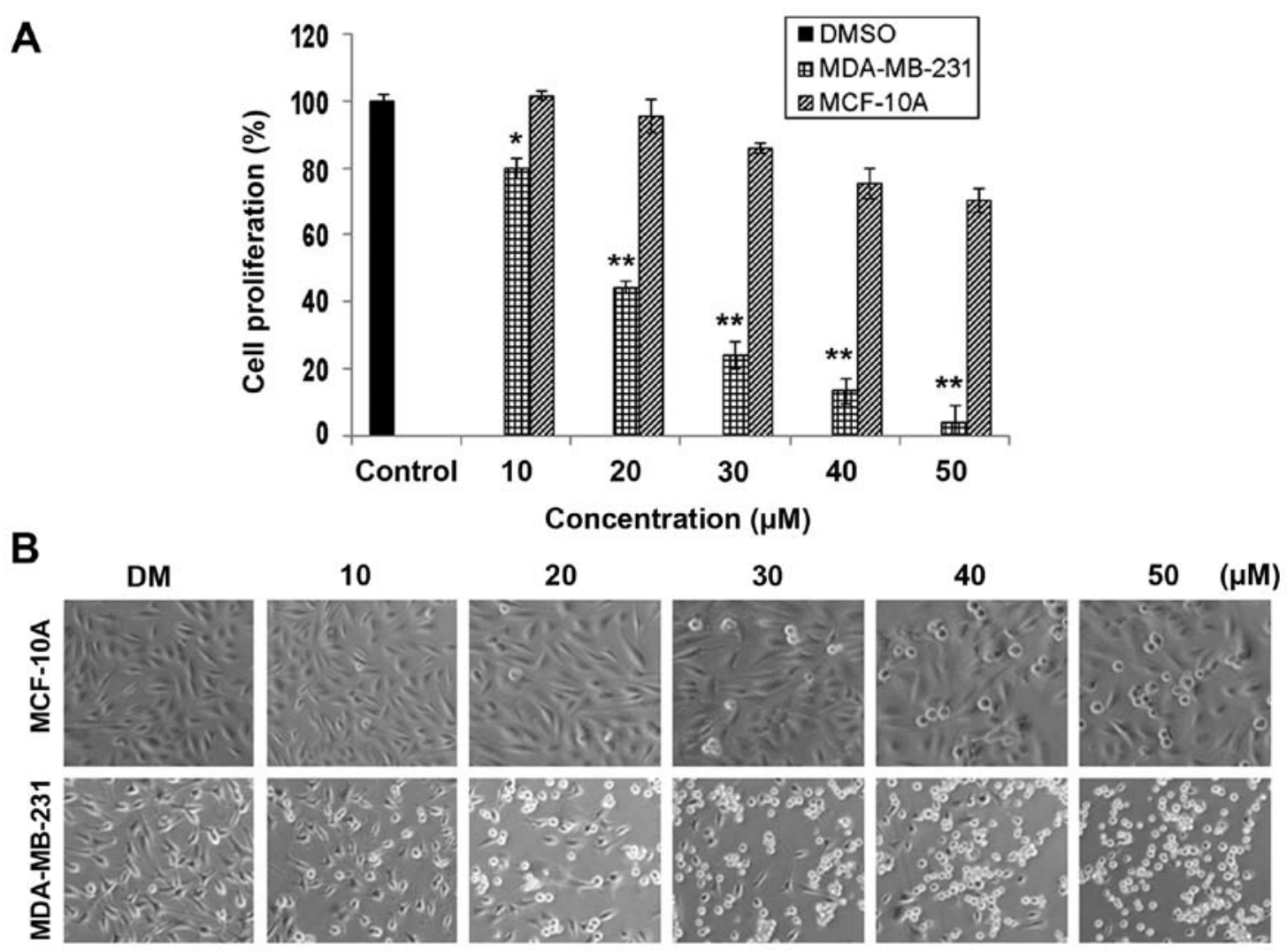

Figure 6. Differential effects of the cefepime plus manganese complex (FEP8) on MDA-MB-231 breast cancer cells and non-tumorigenic MCF-10A breast cells. MDA-MB-231 and MCF-10A Cells were treated with various concentrations of FEP8 or dimethylsulfoxide (DMSO) for $24 \mathrm{~h}$. (A) An MTT assay was performed ${ }^{*} \mathrm{P}<0.05$ and ${ }^{* *} \mathrm{P}<0.01$, compared to control. Bars indicate the means $\pm \mathrm{SD}$ of 3 independent experiments. (B) Morphological changes were observed. Shrunken and rounded MDA-MB-231 cells were observed following treatment with various concentrations of FEP8, whereas little or nearly no morphological changes were observed in the MCF-10A cells.

lines (19-22,52,53). Therefore, combining Mn(II) with several functional molecules has aroused considerable interest for the development of potent anticancer drugs.

We have previously reported that several organic copper and cadmium complexes possess the ability to inhibit proteasome activity and induce apoptosis in human cancer cells $(36,37)$. However, in the present study, we found that only the FEP-Mn complex (FEP8) had the ability to inhibit cell proliferation and proteasome activity (Fig. 2). Therefore, FEP8 was selected for further study. Further experiments indicated that FEP8 inhibited the CT-like activity of the purified $20 \mathrm{~S}$ proteasome (Fig. 3). Moreover, the inhibition of cellular proteasome activity was measured as the decreased levels of CT-like activity and the accumulation of ubiquitinated proteins (Fig. 4). With respect to proteasome-inhibitory activity, this FEP-Mn complex exhibited high activity toward not only the purified 20 S proteasome, but also the proteasome from whole-cell extracts. Cellular morphological changes (shrinkage and rounding) were observed in a concentration-dependent manner (Fig. 4C). In line with these observations, FEP8 also induced the cleavage of PARP to form the p85 fragment (Fig. 4B), indicative of the induction of cell apoptosis. Thus, these results suggest that FEP8 has the potential for development as a novel anticancer agent.

The mechanism of action for the Mn complexes is suggested as follows: i) a Mn complex interacts with DNA and causes DNA damage, ultimately blocking the division of cancer cells and resulting in cell death $(19,20)$; ii) a Mn(II) complex attenuates the absorption of calcium(II) in the mitochondria and interferes with the metabolite of $\mathrm{O}_{2}$ formed by $\mathrm{H}_{2} \mathrm{O}_{2}$ or ROS involved signaling, causing the apoptosis of cancer cells $(21,22,52)$; iii) a Mn complex reduces the number of tumor-associated myeloid-derived suppressor cells, leading to the modulation of the immunosuppressive tumor microenvironment (TME) (53). However, our investigation revealed that the Mn complex (FEP8) inhibited 20S proteasome activity and directly inhibited CT-like activity, which is primarily associated with the $\beta 5$ active site (26). In addition, it has been reported that the decreased proteasomal CT-like activity is associated with the loss of cancer cell availability (35). In this study, it is interesting to note that the Mn complex inhibited proteasomal CT-like activity as early as $3 \mathrm{~h}$ (Fig. 5A), which was consistent with our results demonstrating the accumulation of ubiquitinated proteins and the target protein, IкB- $\alpha$ (Fig. 5B). In addition, changes to cell morphology occurred $9 \mathrm{~h}$ after treatment began (Fig. $5 \mathrm{C}$ ). In summary, our findings indicate that FEP8 has the potential to act as a specific inhibitor of proteasomal CT-like activity and thus to induce cell apoptosis.

A significant challenge in the development of novel anticancer drugs is the safety of metal compounds. Therefore, in this study, we examined whether FEP8 selectively inhibits cell proliferation and induces the apoptosis of MDA-MB-231 breast cancer cells, but not that of normal human MCF-10A breast cells. Indeed, our results demonstrated that the FEP-Mn complex had little effect on MCF-10A cells in contrast to 
its effect on MDA-MB-231 breast cancer cells (Fig. 6). We noted that the FEP-Mn complex is a potent inhibitor of cell proliferation, which is specific to MDA-MB-231 breast cancer cells (Fig. 6A). Also noted was the fact that the MDA-MB-231 cells became detached and rounded when treated with the FEP-Mn complex and almost no toxicity was observed in the MCF-10A cells (Fig. 6B).

In conclusion, the data presented herein suggest that the FEP-Mn complex is a ligand could act as a potent proteasome inhibitor and inducer of apoptosis, and may be a potential anticancer agent targeting breast cancer cells, rather than normal cells. Therefore, this FEP-Mn complex has great potential for development into a drug for cancer treatment. However, further biological analysis and preclinical testing are warranted using animal tumor models.

\section{Acknowledgements}

The authors thank Mr. Maocai Yan for his critical reading of the manuscript. This study was supported by grants from the National Science Foundation of China (no. 21371161 to C.B.) and the Doctoral Foundation of Jining Medical University (no. JY14QD06 to Z.Z).

\section{References}

1. Cunha BA and Gill MV: Cefepime. Med Clin North Am 79 : 721-732, 1995

2. Jándula BM, Martino R, Gurgi M, Manteiga R and Sierra J: Treatment of febrile neutropenia with cefepime monotherapy. Chemotherapy 47: 226-231, 2001.

3. Raad II, Escalante C, Hachem RY, Hanna HA, Husni R, Afif C Boktour MR, Whimbey EE, Kontoyiannis D, Jacobson K, et al: Treatment of febrile neutropenic patients with cancer who require hospitalization: a prospective randomized study comparing imipenem and cefepime. Cancer 98: 1039-1047, 2003.

4. Freifeld AG, Bow EJ, Sepkowitz KA, Boeckh MJ, Ito JI, Mullen CA, Raad II, Rolston KV, Young J-AH and Wingard JR: Clinical practice guideline for the use of antimicrobial agents in neutropenic patients with cancer: 2010 update by the Infectious Diseases Society of America. Clin Infect Dis 52: 56-93, 2011.

5. Saito H, Takahashi K, Okuno M, Saka H, Imaizumi K, Hasegawa Y, Tanikawa Y, Yamamoto M, Taniguchi H, Shindoh J, et al; Central Japan Lung Study Group: Cefepime monotherapy for febrile neutropenia in patients with lung cancer. J Infect Chemother 20: 365-369, 2014

6. Reiss A, Chifiriuc MC, Amzoiu E and Spînu CI: Transition metal (II) complexes with cefotaxime-derived Schiff base: Synthesis, characterization, and antimicrobial studies. Bioinorg Chem Appl 2014: 926287, 2014.

7. Anacona JR and Estacio J: Synthesis and antibacterial activity of cefixime metal complexes. Transit Metab Chem 31: 227-231, 2006.

8. Anacona JR and Lopez M: Mixed-ligand nickel (II) complexes containing sulfathiazole and cephalosporin antibiotics: Synthesis, characterization, and antibacterial activity. Int J Inorg Chem 2012: 1-8, 2012.

9. Anacona JR and Patiño C: Metalloantibiotics: synthesis and antibacterial activity of ceftazidime metal complexes. J Coord Chem 62: 613-621, 2009.

10. Ali AE: Synthesis, spectral, thermal and antimicrobial studies of some new tri metallic biologically active ceftriaxone complexes. Spectrochim Acta A Mol Biomol Spectrosc 78: 224-230, 2011.

11. Sultana N, Arayne MS and Afzal M: Synthesis and antibacterial activity of cephradine metal complexes: part II complexes with cobalt, copper, zinc and cadmium. Pak J Pharm Sci 18: 36-42, 2005.

12. Anacona JR and Rodriguez H: Metalloantibiotics: synthesis and antibacterial activity of cefepime metal complexes. J Coord Chem 62: 2212-2219, 2009.

13. Guo Z and Sadler SP: Metals in medicine. Angew Chem Int 38 1512-1531, 1999.
14. Orvig C and Abrams MJ: Medicinal inorganic chemistry: Introduction. Chem Rev 99: 2201-2204, 1999.

15. Gasser G, Ott I and Metzler-Nolte N: Organometallic anticancer compounds. J Med Chem 54: 3-25, 2011.

16. Faulkner KM, Liochev SI and Fridovich I: Stable Mn(III) porphyrins mimic superoxide dismutase in vitro and substitute for it in vivo. J Biol Chem 269: 23471-23476, 1994.

17. Szabó C, Day BJ and Salzman AL: Evaluation of the relative contribution of nitric oxide and peroxynitrite to the suppression of mitochondrial respiration in immunostimulated macrophages using a manganese mesoporphyrin superoxide dismutase mimetic and peroxynitrite scavenger. FEBS Lett 381: 82-86, 1996.

18. Oliveira CG, da S Maia PI, Souza PC, Pavan FR, Leite CQ, Viana RB, Batista AA, Nascimento OR and Deflon VM: Manganese(II) complexes with thiosemicarbazones as potential anti-Mycobacterium tuberculosis agents. J Inorg Biochem 132: 21-29, 2014

19. Xu ZD, Liu H, Wang M, Xiao SL, Yang $M$ and $\mathrm{Bu} \mathrm{XH:}$ Manganese(II) complex of 6,7-dicycanodipyridoquinoxaline with antitumor activities: synthesis, crystal structure and binding with DNA. J Inorg Biochem 92: 149-155, 2002.

20. Xu ZD, Liu H, Xiao SL, Yang M and Bu XH: Synthesis, crystal structure, antitumor activity and DNA-binding study on the $\mathrm{Mn}(\mathrm{II})$ complex of 2H-5-hydroxy-1,2,5-oxadiazo[3,4-f]1,10phenanthroline. J Inorg Biochem 90: 79-84, 2002.

21. Qiu-Yun C, Dong-Fang Z, Juan H, Wen-Jie G and Jing G: Synthesis, anticancer activities, interaction with DNA and mitochondria of manganese complexes. J Inorg Biochem 104: 1141-1147, 2010.

22. Wang ZW, Chen QY and Liu QS: Manganese (II) complexes of quinoline derivatives: characterization, catalase activity, interaction with mitochondria and anticancer activity. Transit Metab Chem 39: 917-924, 2014.

23. Barbara MO, Mariusz K, Ewa RS, Krystyna GK, Beata FP, Joanna W and Danuta M: Crystal structure, infrared and EPR spectra and anticancer activity in vitro of the novel manganese (II) complexes of indolecarboxylic acids. Polyhedron 67: 464-470, 2014.

24. Nalepa G, Rolfe M and Harper JW: Drug discovery in the ubiquitin-proteasome system. Nat Rev Drug Discov 5: 596-613, 2006.

25. Orlowski RZ and Dees EC: The role of the ubiquitination-proteasome pathway in breast cancer: applying drugs that affect the ubiquitin-proteasome pathway to the therapy of breast cancer. Breast Cancer Res 5: 1-7, 2003.

26. Seemüller E, Lupas A, Stock D, Löwe J, Huber R and Baumeister W: Proteasome from Thermoplasma acidophilum: a threonine protease. Science 268: 579-582, 1995.

27. Glickman $\mathrm{MH}$ and Ciechanover A: The ubiquitin-proteasome proteolytic pathway: Destruction for the sake of construction. Physiol Rev 82: 373-428, 2002.

28. Gallastegui N and Groll M: The 26S proteasome: assembly and function of a destructive machine. Trends Biochem Sci 35: 634-642, 2010

29. Kisselev AF and Goldberg AL: Proteasome inhibitors: from research tools to drug candidates. Chem Biol 8: 739-758, 2001.

30. Adams J, Palombella VJ, Sausville EA, Johnson J, Destree A, Lazarus DD, Maas J, Pien CS, Prakash S and Elliott PJ: Proteasome inhibitors: a novel class of potent and effective antitumor agents. Cancer Res 59: 2615-2622, 1999.

31. Shinohara K, Tomioka M, Nakano $\mathrm{H}$, Toné S, Ito $\mathrm{H}$ and Kawashima S: Apoptosis induction resulting from proteasome inhibition. Biochem J 317: 385-388, 1996.

32. Daniel KG, Gupta P, Harbach RH, Guida WC and Dou QP: Organic copper complexes as a new class of proteasome inhibitors and apoptosis inducers in human cancer cells. Biochem Pharmacol 67: 1139-1151, 2004.

33. An B, Goldfarb RH, Siman R and Dou QP: Novel dipeptidyl proteasome inhibitors overcome $\mathrm{Bcl}-2$ protective function and selectively accumulate the cyclin-dependent kinase inhibitor p27 and induce apoptosis in transformed, but not normal, human fibroblasts. Cell Death Differ 5: 1062-1075, 1998.

34. Lopes UG, Erhardt P, Yao R and Cooper GM: p53-dependent induction of apoptosis by proteasome inhibitors. J Biol Chem 272: 12893-12896, 1997.

35. Verani CN: Metal complexes as inhibitors of the $26 \mathrm{~S}$ proteasome in tumor cells. J Inorg Biochem 106: 59-67, 2012.

36. Zhang Z, Bi C, Schmitt SM, Fan Y, Dong L, Zuo J and Dou QP: 1,10-Phenanthroline promotes copper complexes into tumor cells and induces apoptosis by inhibiting the proteasome activity. J Biol Inorg Chem 17: 1257-1267, 2012. 
37. Zhang Z, Bi C, Buac D, Fan Y, Zhang X, Zuo J, Zhang P, Zhang N, Dong L and Dou QP: Organic cadmium complexes as proteasome inhibitors and apoptosis inducers in human breast cancer cells. J Inorg Biochem 123: 1-10, 2013.

38. Daniel KG, Chen D, Orlu S, Cui QC, Miller FR and Dou QP. Clioquinol and pyrrolidine dithiocarbamate complex with copper to form proteasome inhibitors and apoptosis inducers in human breast cancer cells. Breast Cancer Res 7: R897-R908, 2005.

39. Chen D, Peng F, Cui QC, Daniel KG, Orlu S, Liu J and Dou QP: Inhibition of prostate cancer cellular proteasome activity by a pyrrolidine dithiocarbamate-copper complex is associated with suppression of proliferation and induction of apoptosis. Front Biosci 10: 2932-2939, 2005.

40. Chen D, Cui QC, Yang H, Barrea RA, Sarkar FH, Sheng S, Yan B, Reddy GPV and Dou QP: Clioquinol, a therapeutic agent for Alzheimer's disease, has proteasome-inhibitory, androgen receptor-suppressing, apoptosis-inducing, and antitumor activities in human prostate cancer cells and xenografts. Cancer Res 67 1636-1644, 2007

41. Xiao Y, Bi C, Fan Y, Cui C, Zhang X and Dou QP: L-glutamine Schiff base copper complex as a proteasome inhibitor and an apoptosis inducer in human cancer cells. Int J Oncol 33: 1073-1079, 2008.

42. Zhang X, Bi C, Fan Y, Cui Q, Chen D, Xiao Y and Dou QP: Induction of tumor cell apoptosis by taurine Schiff base copper complex is associated with the inhibition of proteasomal activity. Int J Mol Med 22: 677-682, 2008.

43. Li L, Yang H, Chen D, Cui C and Dou QP: Disulfiram promotes the conversion of carcinogenic cadmium to a proteasome inhibitor with pro-apoptotic activity in human cancer cells. Toxicol Appl Pharmacol 229: 206-214, 2008.

44. Cvek B, Milacic V, Taraba J and Dou QP: Ni(II), Cu(II), and $\mathrm{Zn}$ (II) diethyldithiocarbamate complexes show various activities against the proteasome in breast cancer cells. J Med Chem 51: 6256-6258, 2008.
45. Li B and Dou QP: Bax degradation by the ubiquitin/ proteasome-dependent pathway: Involvement in tumor survival and progression. Proc Natl Acad Sci USA 97: 3850-3855, 2000.

46. Dou QP and Li B: Proteasome inhibitors as potential novel anticancer agents. Drug Resist Updat 2: 215-223, 1999.

47. Goldberg AL: Functions of the proteasome: the lysis at the end of the tunnel. Science 268: 522-523, 1995.

48. Hindo SS, Frezza M, Tomco D, Heeg MJ, Hryhorczuk L, McGarvey BR, Dou QP and Verani CN: metals in anticancer therapy: Copper(II) complexes as inhibitors of the $20 \mathrm{~S}$ proteasome. Eur J Med Chem 44: 4353-4361, 2009.

49. Chen D, Milacic V, Frezza M and Dou QP: Metal complexes, their cellular targets and potential for cancer therapy. Curr Pharm Des 15: 777-791, 2009.

50. Li X, Zhao K, Guo W, Liu X, Liu J, Gao J, Chen Q and Bai Y: A novel manganese complex LMnAc selectively kills cancer cells by induction of ROS-triggered and mitochondrial-mediated cell death. Sci China Life Sci 57: 998-1010, 2014.

51. Aschner M, Ruilarte TR, Schneider JS and Zheng W: Manganese: recent advances in understanding its transport and neurotoxicity. Toxicol Appl Pharmacol 221: 131-147, 2007.

52. Zhou DF, Chen QY, Qi Y, Fu HJ, Li Z, Zhao KD and Gao J: Anticancer activity, attenuation on the absorption of calcium in mitochondria, and catalase activity for manganese complexes of N-substituted di(picolyl)amine. Inorg Chem 50: 6929-6937, 2011.

53. Das S, Banerjee K, Roy S, Majumder S, Chatterjee M, Majumdar S and Choudhuri SK: Mn complex-mediated enhancement of antitumor response through modulating myeloid-derived suppressor cells in drug-resistant tumor. In Vivo 28: 909-918, 2014. 